\title{
Computer-based Automated System for Determining the Characteristics, Losses and Efficiency of Separately Excited DC Motors
}

\author{
Puneet Kaur* and S. Chatterji**
}

\begin{abstract}
This paper provides essential information on research completed with the aim to develop a 'dc motor test and analysis platform' which can be used to provide de motor characteristics, calculate losses and efficiency, and also work as a dc motor speed controller. A user can test a given de motor for these analyses by practicing different conventional methods, but, the concept discussed in this paper, reveals how intelligent integration of all these analyses can be done with a single user friendly automated setup. Integration has been accomplished by a technique that can accommodate all types of de motors with different ratings at various loading conditions. However, experimentally measured results of a $0.5 \mathrm{HP}$ separately excited de motor using the discussed scheme are presented in the paper. Also, a comparison of the methodology of this system with conventional techniques has also been elaborated on to show the effectiveness of the system.
\end{abstract}

Keywords: Data acquisition, Electrical loading of dc motor, Motor torque, Performance-index of dc motor, Speed-torque characteristics.

\section{Introduction}

Experimental determination of characteristics of dc motors is quite important for prediction of their accurate performance. Also, compatibility of a dc motor for any type of application can be best understood by analyzing their speed-torque characteristics. On the other hand, correct and accurate calculation of losses and efficiency has been established as an important means for detection of faults in dc motors. Therefore, an essential criterion for deciding the performance-index for dc motors is a knowledge of their speed-torque characteristics, losses (constant and variable) occurring in the motor and measurement of their efficiency.

Review of conventional technologies practiced reveals the limitations and constraints of these methodologies. It has been surveyed that no single test or methodology already available or published can provide a total automated solution to acquire all the important parameters of a dc motor which are required for its performance evaluation.

In this paper, the concept of PC based automated acquisition of speed-torque characteristics in real-time, calculation of losses, efficiency versus torque curve and closed loop speed control of a dc motor is discussed. By practicing this single automated method, various parameters of a dc motor e.g. speed, torque, armature current, field current, armature voltage, field voltage, winding temperature variations and dependency of these parameters on each other are closely monitored with help of control hardware and

\footnotetext{
* Assistant Professor, Department of Electrical \& Electronics Engineering, UIET, Panjab University, Chandigarh, India. puneet2379@yahoo.com)

** Prof \& Head, Department of Electrical Engineering, NITTTR, Chandigarh, India.(chatterjis@yahoo.com)
}

application software. The novelty of the scheme presented is the way as the control of the scheme is implemented.

The embedded scheme has been developed using an external interface hardware based on an AVR microcontroller, a data acquisition card, and a graphical programming environment (visual basic).

The control hardware presented in this paper is an AVR based embedded system, dedicatedly designed for providing complete automation for the evaluation of dc motors. It has been programmed with a firmware, which performs all the tasks necessary to execute a dc motor control application. The developed ' $\mathrm{dc}$ motor test and analysis platform' controls the motor input dc voltage/s through SCR bridges, electrically loads the dc motor through a dc generator, collects the motor parameters at each loading condition and manipulates the acquired data in PC based software to arrive at the parameters which will define the motor performance.

The graphical programming method allows a high degree of software modularity and automated presentation of results, whereas capabilities of the AVR microcontroller are utilized for data acquisition, SCR bridge control and RS232 serial communication [1]-[3].

\section{Methodology of conventional techniques for testing of separately excited dc motor}

It was surveyed that conventional set-ups make use of two types of methodologies for performing load-tests on dc motors [4]-[7]. One set-up involves use of mechanically coupling 'a brake drum' (i.e pulley-belt arrangement) with spring balance on both sides as shown in Figure 1. 
To increase the load torque, the tension on the two belt portions, is adjusted for an increased difference. The dc motor is started with help of a starter and brought to its rated speed.By adjusting the spring tensions, the motor is loaded from its no-load to full-load and readings of the measuring devices are noted down for further calculations of torque and other necessary parameters.

The other method of loading involves use of a dc generator coupled with a test dc motor, along with other essential electrical measuring devices as shown in Figure 2. The separately excited dc motor is started with the help of a starter, and brought to its rated speed with the help of a field-current-rheostat of motor. The dc generator is run to obtain its terminal voltage with the help of the field rheostat of generator. The generator is then loaded with help of its loading rheostat, keeping its terminal voltage constant. Reading of measuring devices is observed while the entire range of no-load to full-load of the motor are covered.

In both of the methodologies, in order to collect the final results, a lot of manual computations/calculations of observed parameters are required. Not only this, multiple tests at different loads and different speeds of separately excited dc motors are essential to cover the complete operating range of the dc motor with use of such conventional techniques. As the measuring instruments used in the set-up are chosen according to the rating of a separately excited dc motor, for testing higher (or lower) rating of the separately excited dc motor, the entire set-up needs to be modified. Similarly, modification in the set-up will also be required for testing different types of dc motors. As a result, if one tries to evaluate a dc motor for its characteristics, losses and efficiency with the current available techniques, the process becomes time-consuming, cumbersome, error prone and tedious.

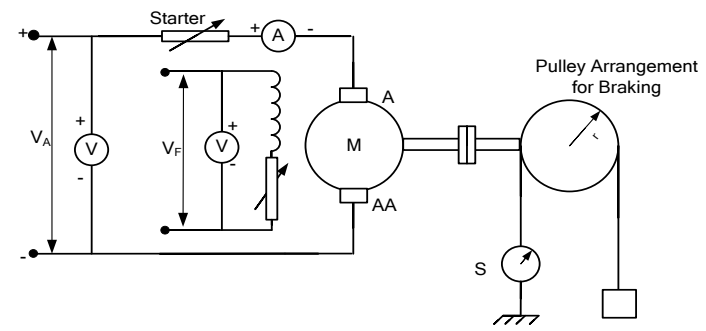

Fig.1. Conventional Loading Methodology 1 for Separately Excited DC Motor

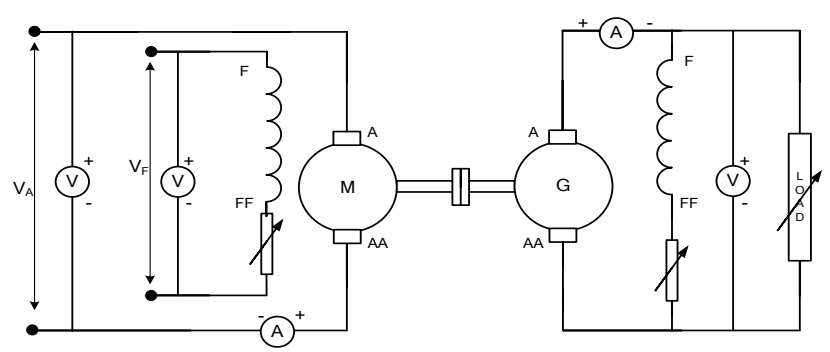

Fig.2. Conventional Loading Methodology 2 for Separately Excited DC Motor

\section{Automated de motor test and analysis platform}

The previous section establishes the scope for the work undertaken by the investigators in the present paper. This also explains how the presented work has been derived out of the previous works already carried out in this area of research. Automation helps in minimizing the operator intervention to change setups in order to carry out different tests on one motor. Complex calculations, derivations and controls get off loaded from the operator and are integrated in the automated tests. The user after carrying out performance testing will be able to record the test data for future reference. The platform has a user friendly PC based graphical interface for control of various operations.

The platform for automating the process of testing of any given separately excited dc motor consists of a separately excited dc motor (under test) coupled with a separately excited dc generator, which is interfaced with the control hardware and PC. The generator itself is electrically loaded by connecting suitable fixed resistance at its terminals. The interconnection topology of the discussed automated test platform is shown in Figure 3.

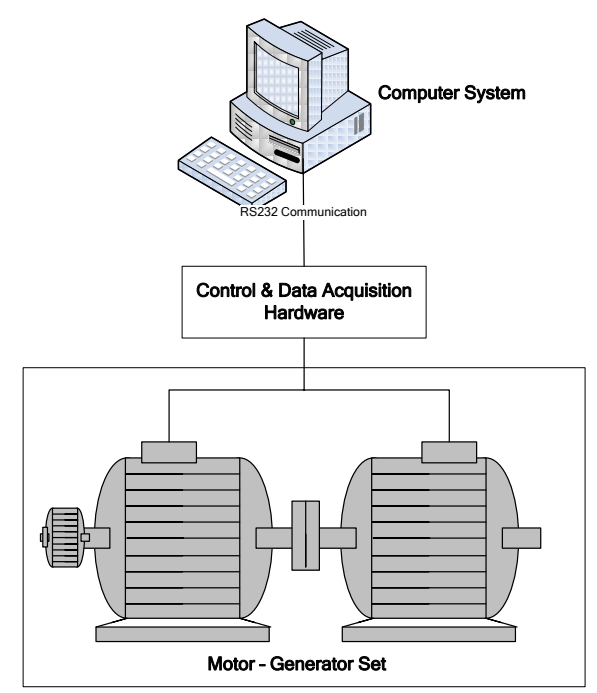

Fig. 3. Automated test platform for testing separately excited DC Motor

The control hardware platform for this system is designed around an AVR series microcontroller ATMega32 [8], whose various on-chip peripherals are utilized for the purpose of data acquisition, motor controls and communication with the PC.

Different motor parameters like motor current, motor voltage, generator field voltage, speed and winding temperature are acquired by the analog to digital converter (ADC) port of microcontroller after being filtered and conditioned by a signal conditioning section. These analog signals are acquired from different sensors like a Hall Effect Current Transducer (2.5 V full scale output for 25 A current) to acquire motor current, tachogenerator $(30 \mathrm{~V}$ full scale 
voltage output for $1500 \mathrm{r} / \mathrm{min}$ ) to acquire motor shaft speed and an NTC Thermistor(operating temperature range -30 to $120^{\circ} \mathrm{C}$ ) to acquire the temperature of the dc motor winding. For acquiring dc motor and dc generator voltage signals, resistive voltage divider circuits are used.(ATMega 32 has an integrated analog to digital converter with 8 multiplexed analog input channels, 10-bit resolution and $15 \mathrm{Ksps}$ maximum sampling rate).

Output signals obtained from the various sensors are conditioned by a signal conditioning section to make them compatible with the ADC inputs of the microcontroller. Current and voltage signals have been filtered by using a low pass second order active filter whereas the temperature sensor output has been filtered using a passive low pass filter. The speed signal is received from tachogenerator, so the electrical signal is first rectified using a diode and capacitor before filtering the same.

A microcontroller based hardware is also configured to provide digital inputs and outputs. Digital inputs are used to acquire signals coming from the zero crossing detector (to detect the phase of incoming ac voltage), limit switches, proximity switches or push buttons. Digital outputs in this hardware are primarily meant to drive the SCRs and hence are interfaced to pulse transformers using power transistors. Digital output pins can be optionally used to generate PWM and relay control signals also [9].

A microcontroller UART is configured for 115200 bits per second baud rate to communicate with PC RS232 port. A voltage level shifter IC is used to convert $0-5 \mathrm{~V}$ signal levels of microcontroller to RS232 voltage levels and viceversa.

The firmware of the microcontroller which is responsible for performing tasks like firing of SCRs, data acquisition, relay control, serial UART communication, PID control, digital filters etc, has been developed in embedded Clanguage using an AVR-GCC compiler[10].

Since, the control hardware communicates with the PC via the RS-232 serial port, a PC program based on Microsoft Windows is designed to provide the necessary interface to the user and also interaction with the hardware. This PC based application software gives provision for choosing different type of tests to be performed, editing/updating information regarding motor set-up viz. rating of machines, rated speed, rated voltage, rated current; armature resistance, field resistance etc, which is used to calculate the dc motor copper losses and efficiency. Also, application software provides provision for test data storage in ASCII text format, data processing and visualization of results in graphical and tabular form.

The methodology involved in this automated technique revolves around the fact that generator output voltage (voltage at the generator armature terminals) is proportional to shaft speed, magnetic field strength and number of conductor loops in the armature. Since the last parameter stays constant for a test, it is clear that any change in motor shaft loading caused by a reduction in speed can be compensated by increase in generator field voltage (magnetic field strength) and vice versa.

When the generator armature is connected to the electrical load, it applies a mechanical opposition to the rotation of shaft. This shaft loading is utilized to test the behavior of the motor under different loading conditions.

As discussed in the previous section, in conventional methods, the dc motor (under test) is loaded by adding electrical load to the generator output and keeping the generator field excitation voltage constant. During the motor performance testing, there is a requirement to achieve the constant mechanical loading of the motor shaft. The fact that mechanical loading of the motor shaft is dependent on speed makes it difficult and impractical to achieve the same.

Authors have utilized the microcontroller's processing power to achieve a precise PID control of motor shaft loading by manipulating the generator field voltage. In this case, the electrical load on the generator armature is fixed whereas the field voltage of the generator is varied by a fully controlled SCR Bridge.

\section{Methodologies of automated tests carried out for separately excited dc motor}

a) Characteristics of the dc motor: Initially the $\mathrm{dc}$ motor is run at maximum speed (rated voltage) and at noload (generator field turned off). Gradually mechanical load on the motor shaft is increased by increasing the reference (target value) input to the PID control algorithm which controls the generator field. The PID algorithm output manipulates the firing-angle of the SCR bridge which in turn controls the voltage being fed to the generator field. Voltage across the armature terminals of the generator (armature terminated with fixed resistor) acts as the feedback signal for the PID control algorithm. Real time values of motor parameters e.g. voltage, current, speed, winding temperature, etc. acquired by the microcontroller at predefined intervals during the test, are sent to the PC, where storing in the log file for analysis and plotting of the characteristics are carried out. Calculations of the motor torque from the data provided by the microcontroller is carried out in the PC software using the torque equation.

b) Motor Efficiency and Copper loss: In this test, losses occurring in the dc generator also need to be considered to calculate the motor efficiency. This is done in order to ensure correct calculation of the mechanical power delivered by the motor. This is achieved by carrying out the generator calibration (process in which generator constant losses are calculated for different speeds) before conduct of the tests. During conduct of tests, real time values of motor parameters e.g. motor voltage, current, speed, winding temperature etc. are acquired at predefined intervals and they are sent to the PC for storing in the log file, further processing and display of results. Calculations for motor torque, variable and constant losses of the motor, power input, power output and efficiency of motor are carried out 
in the PC software in accordance with real time acquisition of motor parameters and specifications of the motor entered by the user.

c) Motor speed controller: In this mode, the feedback signal is acquired from the tachogenerator and the value of firing-angle of the SCR bridge for the motor voltage control is manipulated to achieve the desired speed. In this mode a graph is plotted over the time scale along with the motor armature current. Motor shaft loading can also be controlled in this test.

Block diagram for the automated scheme is illustrated in Figure 4.

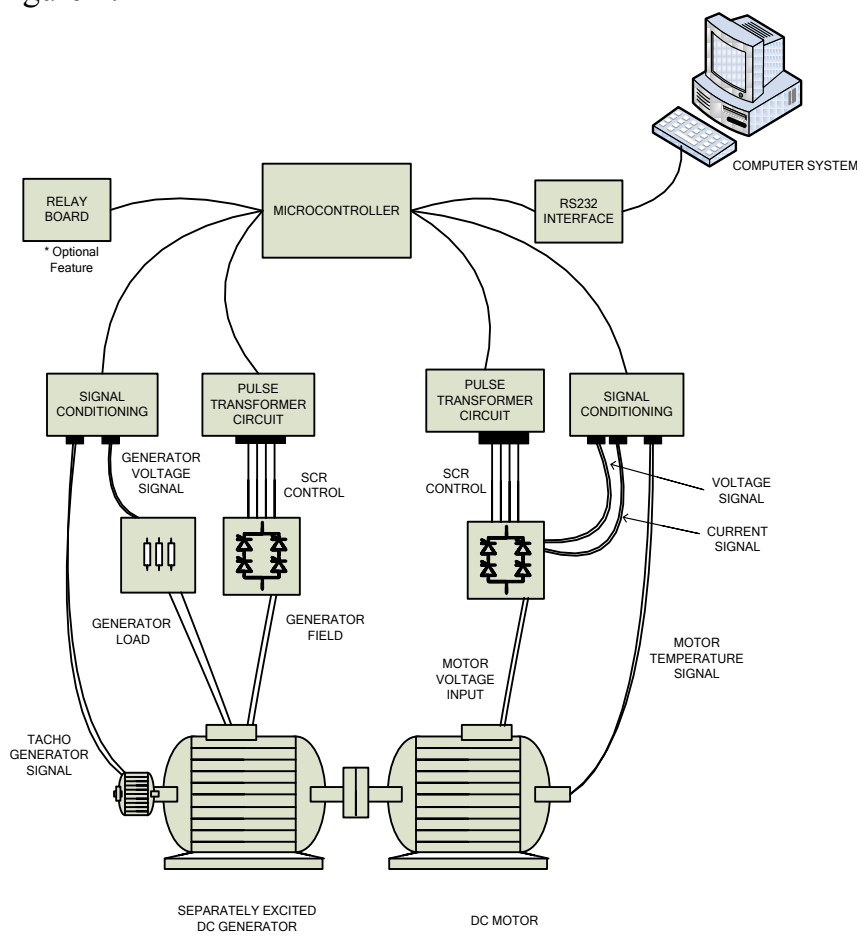

Fig. 4. Block diagram of the automated scheme for testing of Separately Excited DC motor

\section{Calculation of DC Motor Parameters}

\subsection{Details for acquiring Motor Characteristics}

In this analysis, the separately excited motor is run at the rated speed and loading of motor shaft is increased gradually in a controlled manner. Other than the start and the stop commands sent by the $\mathrm{PC}$, all the other operations are executed at regular intervals by the microcontroller timer interrupt service subroutine. During the performance of these tests motor parameters like speed, line current, motor voltage etc are read by the microcontroller and the digital data is sent to the PC. The PC software calculates from this information the complex parameters like torque, armature current, back emf etc. PC software calculations are based on the motor specifications entered by the user.

In order to illustrate the working of the automated scheme, formulae are provided for calculation of armature current, emf and torque by the application software.

\section{(1) Calculation of Armature current}

$$
I_{a}=I_{L}
$$

where, Ia is the motor armature current (calculated by software) IL is the motor line current (real time acquisition)

\section{(2) Back emf calculation}

Calculation of back emf is essential to arrive at the correct value of torque delivered by the motor. This calculation is also carried out in the application software by formula given below:

$$
E_{b}=V-I_{a} R_{a}
$$

where, $R_{a}$ is the motor armature resistance (provided by user) $\mathrm{V}$ is the motor terminal voltage (real time acquisition)

\section{(3) Calculation of Torque}

General formula used for calculation of torque is given by:

$$
\mathrm{T}_{\mathrm{m}}=\frac{\mathrm{E}_{\mathrm{b}} \mathrm{l}_{\mathrm{a}}}{2 \pi} \frac{60}{\mathrm{~N}}
$$

where, $T_{m}$ is the generated Torque in $\mathrm{Nm}$ (calculated by software) $\mathrm{N}$ is the speed of motor in rev/min (real time acquisition)

\subsection{Details for acquiring Motor Efficiency and Copper Losses}

Test sequence in this motor analysis is similar to the one listed above, except that the calculations are carried out for motor efficiency and the copper losses. Formula for one such calculation for a shunt motor is given below:

Copper loss in motor $=$ Copper loss in armature + copper loss in field or,

$$
\text { Copper loss in motor }=I_{a}^{2} R_{a}+I_{f}^{2} R_{f}
$$

where, $R_{f}$ is the field resistance(provided by user) Thus, copper loss of motor is calculated by the software.

Efficiency of the motor is calculated as a ratio of mechanical output power delivered by the motor, to the electrical input power. In this automated scheme, input power is calculated by multiplying the input motor voltage with the motor line current.

In order to calculate the output power delivered by the motor, the losses and the electrical power of the generator have to be considered. Following equations summarize the total output delivered by the motor. 
Output delivered by the motor $=$ Electrical power output of the generator + generator copper loss + generator fixed losses.

Generator fixed losses at different speeds have been calculated during generator calibration process and stored in the application software for reference, and generator copper losses is calculated by formula:

$$
\text { Copper loss in generator }=V_{G e n}{ }^{2} / R_{L}
$$

where, $\mathrm{V}_{\mathrm{Gen}}$ is terminal voltage of generator (real time acquisition) $\quad R_{L}$ is fixed generator load resistance (provided by user)

Finally calculation for motor efficiency is carried out by formula given below:

\section{Efficiency of the motor = output delivered by the motor / input power to the motor}

\subsection{Details of the motor evaluation (speed controller mode)}

In this case the user can change the speed and also generator field to run the motor under different speeds and loading conditions. Motor speed and armature current have been plotted in a graph in real time. X-axis of this graph represents the time scale shown as number of samples acquired during the test. In this test, speed and load adjustment commands are sent to the control hardware whenever the user presses the command buttons. These commands are acknowledged by the microcontroller firmware and the motor voltage is altered either by modifying the firing-angle of the SCR Bridge or by changing the motor loading by way of modifying the generator field voltage. Motor parameters are continuously acquired during the test and sent to the $\mathrm{PC}$ at regular intervals.

\section{Automated test results}

The system presented in the paper after fabrication was tested and validated using $0.5 \mathrm{HP}$ separately excited dc motor-generator (MG) set (practical set-up as shown in Figure 5). Results of various analyses (viz. to obtain speedcurrent, torque-current and speed-torque characteristics curves, to calculate dc motor losses and obtaining efficiency curve, to run dc motor in speed controller mode) were captured on PC using Visual Basic Application software in form of curves as well as in tabular form so that practical performance of dc motor can be verified with data derived from theoretical calculations and equations.

For illustration of the results, various graphs have been presented in form of screen shots shown from Figure 6 to Figure 10 and sample values of parameters captured and recorded by the PC application software during the test have been provided in Table 1 to Table 4 .

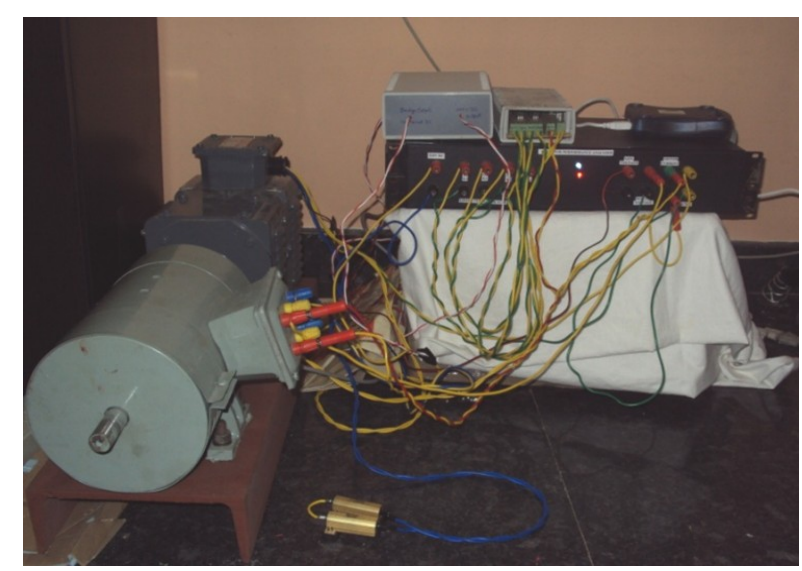

Fig. 5. Practical Set-up for Testing Separately Excited DC Motors

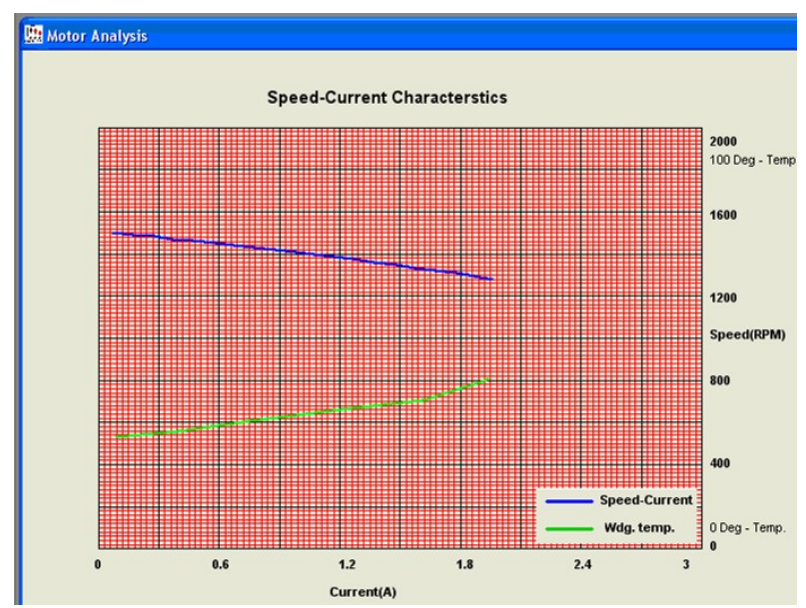

Fig. 6. Screen-shot of Speed-Current Characteristic of Separately excited DC Motor

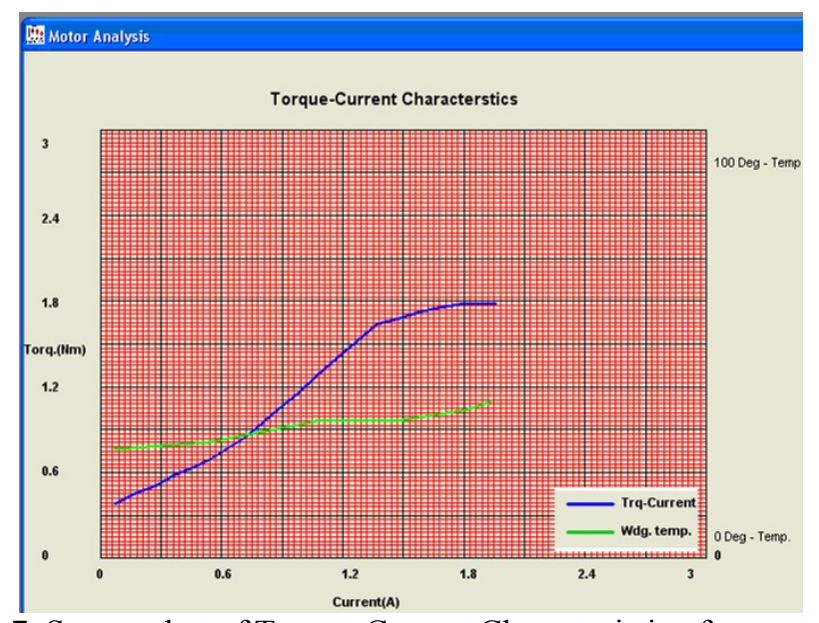

Fig.7. Screen-shot of Torque-Current Characteristic of Separately excited DC Motor 


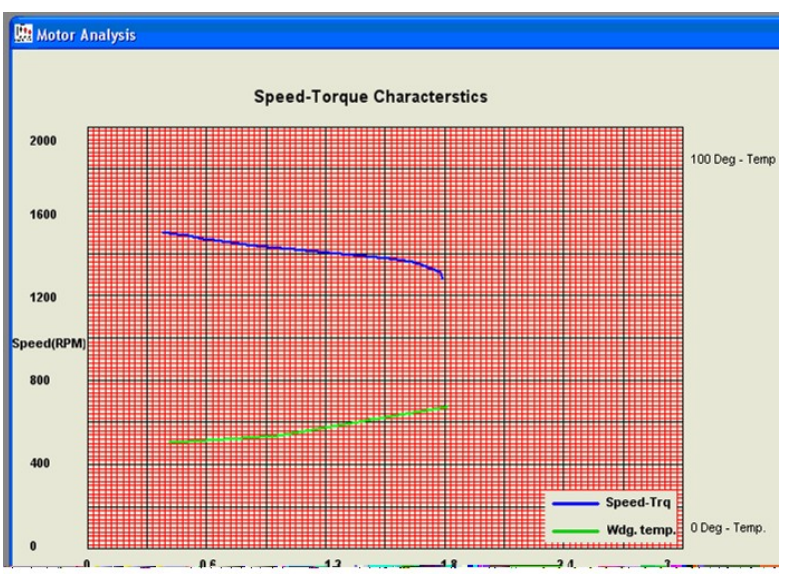

Fig. 8. Screen-shot of Speed-Torque Characteristic of Separately excited DC Motor

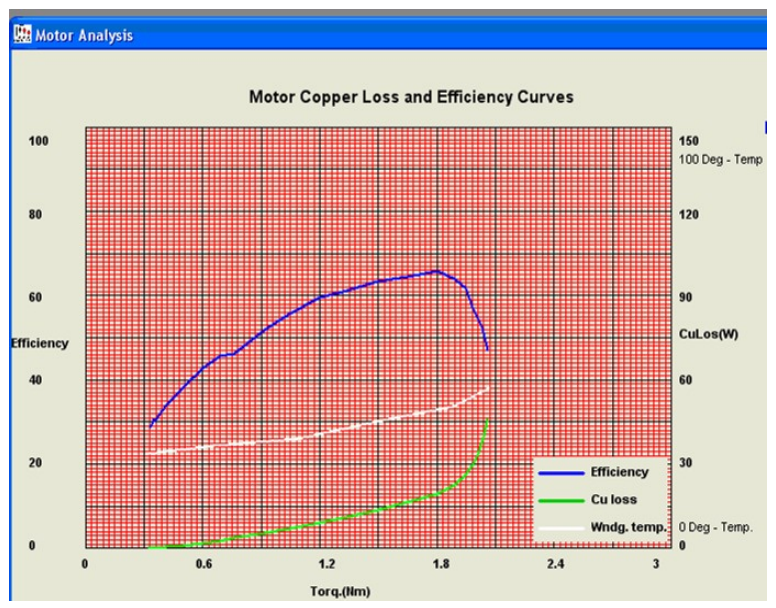

Fig. 9. Screen-shot of Calculation of Losses and Efficiency of Separately excited DC Motor

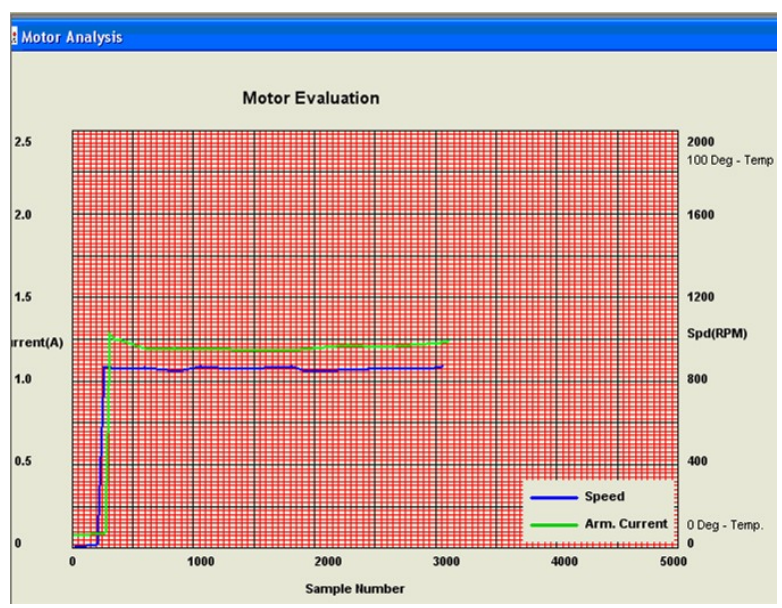

Fig. 10. Screen-shot of Evaluation of Separately excited DC Motor
Torque-Current Characteristic

\begin{tabular}{|c|c|c|c|c|}
\hline $\begin{array}{l}\text { Motor Voltage } \\
\text { (V) }\end{array}$ & $\begin{array}{l}\text { Field Current } \\
\text { (A) }\end{array}$ & Torque (Nm) & $\begin{array}{c}\text { Armature } \\
\text { Current (A) }\end{array}$ & $\begin{array}{c}\text { Winding } \\
\text { Temperature } \\
\text { (oC) }\end{array}$ \\
\hline 205 & 0.41 & 0.44 & 0.5 & 28 \\
\hline 206 & 0.412 & 0.56 & 0.6 & 28 \\
\hline 204 & 0.408 & 0.67 & 0.7 & 28 \\
\hline 208 & 0.416 & 0.79 & 0.8 & 29 \\
\hline 208 & 0.416 & 0.91 & 0.9 & 29 \\
\hline 204 & 0.408 & 1.01 & 1 & 29 \\
\hline 208 & 0.416 & 1.22 & 1.1 & 30 \\
\hline 206 & 0.412 & 1.4 & 1.2 & 30 \\
\hline 202 & 0.404 & 1.58 & 1.3 & 31 \\
\hline 204 & 0.408 & 1.77 & 1.4 & 26 \\
\hline 206 & 0.412 & 2 & 1.5 & 34 \\
\hline 208 & 0.416 & 2.19 & 1.6 & 36 \\
\hline 208 & 0.416 & 2.39 & 1.7 & 37 \\
\hline 206 & 0.412 & 2.51 & 1.8 & 39 \\
\hline 204 & 0.408 & 2.6 & 1.9 & 40 \\
\hline 207 & 0.414 & 2.63 & 2 & 40 \\
\hline 205 & 0.41 & 2.67 & 2.1 & 43 \\
\hline 202 & 0.404 & 2.71 & 2.2 & 47 \\
\hline 206 & 0.412 & 2.74 & 2.39 & 50 \\
\hline
\end{tabular}

Table 2. Values of Parameters Generated for Plotting Speed-Current Characteristic

\begin{tabular}{|c|c|c|c|c|c|}
\hline $\begin{array}{c}\text { Motor } \\
\text { Vottage } \\
(\mathbf{V})\end{array}$ & $\begin{array}{c}\text { Field } \\
\text { Current (A) }\end{array}$ & $\begin{array}{c}\text { Speed } \\
\text { (RPM) }\end{array}$ & $\begin{array}{c}\text { Torque } \\
\text { (Nm) }\end{array}$ & $\begin{array}{c}\text { Armature } \\
\text { Current (A) }\end{array}$ & $\begin{array}{c}\text { Winding } \\
\text { Temperature } \\
\text { (oC) }\end{array}$ \\
\hline 205 & 0.41 & 1498 & 0.44 & 0.5 & 27 \\
\hline 206 & 0.412 & 1495 & 0.56 & 0.6 & 27 \\
\hline 204 & 0.408 & 1490 & 0.67 & 0.7 & 28 \\
\hline 208 & 0.416 & 1490 & 0.79 & 0.8 & 28 \\
\hline 208 & 0.416 & 1481 & 0.91 & 0.9 & 29 \\
\hline 204 & 0.408 & 1472 & 1.01 & 1 & 29 \\
\hline 208 & 0.416 & 1463 & 1.22 & 1.1 & 29 \\
\hline 206 & 0.412 & 1452 & 1.4 & 1.2 & 30 \\
\hline 202 & 0.404 & 1431 & 1.58 & 1.3 & 30 \\
\hline 204 & 0.408 & 1412 & 1.77 & 1.4 & 31 \\
\hline 206 & 0.412 & 1392 & 2 & 1.5 & 31 \\
\hline 208 & 0.416 & 1373 & 2.19 & 1.6 & 34 \\
\hline 208 & 0.416 & 1354 & 2.39 & 1.7 & 37 \\
\hline 206 & 0.412 & 1331 & 2.51 & 1.8 & 40 \\
\hline 204 & 0.408 & 1312 & 2.6 & 1.9 & 42 \\
\hline 207 & 0.414 & 1292 & 2.63 & 2.1 & 44 \\
\hline 205 & 0.41 & 1271 & 2.67 & 2.1 & \\
\hline
\end{tabular}

Table 1. Values of Parameters Generated for Plotting 
Table 3. Values of Parameters Generated for Plotting Speed-Torque Characteristic

\begin{tabular}{|c|c|c|c|c|c|}
\hline $\begin{array}{c}\text { Armature } \\
\text { Current } \\
\text { (A) }\end{array}$ & $\begin{array}{l}\text { Variable } \\
\text { (Copper) } \\
\text { Loss (W) } \\
\end{array}$ & $\begin{array}{c}\begin{array}{c}\text { Constant } \\
\text { (Iron) }\end{array} \\
\text { Loss (W) }\end{array}$ & $\begin{array}{c}\text { Input } \\
\text { Power } \\
\text { (W) }\end{array}$ & $\begin{array}{c}\text { Efficiency } \\
(\%)\end{array}$ & $\begin{array}{c}\text { Torque } \\
\text { (Nm) }\end{array}$ \\
\hline 0.16 & 0.07 & 21 & 122.4 & 29.1 & 0.4 \\
\hline 0.28 & 0.35 & 22 & 143.8 & 33.8 & 0.5 \\
\hline 0.35 & 0.87 & 22 & 167.4 & 38.2 & 0.6 \\
\hline 0.48 & 1.64 & 21 & 186.9 & 42.5 & 0.7 \\
\hline 0.57 & 2.65 & 22 & 205 & 45.6 & 0.8 \\
\hline 0.66 & 3.9 & 21 & 227.8 & 46.3 & 0.9 \\
\hline 0.77 & 5.4 & 21 & 247.2 & 52 & 1.1 \\
\hline 0.87 & 7.12 & 22 & 262.6 & 55.7 & 1.2 \\
\hline 0.97 & 9.29 & 22 & 286.6 & 59.6 & 1.3 \\
\hline 1.07 & 11.29 & 23 & 309 & 61.2 & 1.5 \\
\hline 1.17 & 13.74 & 21 & 332.8 & 63.5 & 1.7 \\
\hline 1.28 & 16.43 & 21 & 353.6 & 64.5 & 1.8 \\
\hline 1.37 & 19.35 & 23 & 370.8 & 65.7 & 1.9 \\
\hline 1.48 & 22.52 & 22 & 386.9 & 63.8 & 2 \\
\hline 1.57 & 26.28 & 23 & 414 & 61.7 & 2 \\
\hline 1.66 & 29.58 & 24 & 430.5 & 57.3 & 2 \\
\hline 1.78 & 33.47 & 24 & 443.4 & 54.5 & 2 \\
\hline 1.97 & 38.02 & 23 & 491.3 & 52.5 & 2.1 \\
\hline
\end{tabular}

Table 4. Values of Parameters Generated for Motor Losses and Efficiency

\begin{tabular}{|c|c|c|c|c|}
\hline $\begin{array}{c}\text { Motor Voltage } \\
\text { (V) }\end{array}$ & $\begin{array}{l}\text { Field } \\
\text { Current } \\
\text { (A) }\end{array}$ & $\begin{array}{c}\text { Armature } \\
\text { Current (A) }\end{array}$ & $\begin{array}{l}\text { Speed } \\
\text { (RPM) }\end{array}$ & $\begin{array}{c}\text { Winding } \\
\text { Temperature } \\
\left({ }^{\circ} \mathrm{C}\right)\end{array}$ \\
\hline 206 & 0.427 & 0.07 & 1497 & 27 \\
\hline 206 & 0.429 & 0.17 & 1494 & 27 \\
\hline 204 & 0.425 & 0.27 & 1491 & 27 \\
\hline 208 & 0.433 & 0.37 & 1490 & 28 \\
\hline 207 & 0.433 & 0.47 & 1483 & 28 \\
\hline 204 & 0.425 & 0.57 & 1473 & 28 \\
\hline 208 & 0.433 & 0.67 & 1461 & 28 \\
\hline 206 & 0.429 & 0.77 & 1452 & 29 \\
\hline 202 & 0.42 & 0.88 & 1431 & 29 \\
\hline 204 & 0.425 & 0.97 & 1412 & 29 \\
\hline 206 & 0.429 & 1.07 & 1392 & 29 \\
\hline 208 & 0.433 & 1.17 & 1373 & 30 \\
\hline 208 & 0.433 & 1.27 & 1354 & 30 \\
\hline 206 & 0.429 & 1.37 & 1331 & 32 \\
\hline 204 & 0.425 & 1.48 & 1312 & 35 \\
\hline 207 & 0.431 & 1.57 & 1291 & 37 \\
\hline 205 & 0.427 & 1.67 & 1271 & 40 \\
\hline 202 & 0.42 & 1.78 & 1263 & 43 \\
\hline 206 & 0.429 & 1.96 & 1240 & 45 \\
\hline
\end{tabular}

\section{Conclusion}

The validity of the test results can thus be checked by comparing the test results obtained from this automated procedure with experimentally measured results obtained by conventional methodology using higher precision measurement equipment. The effectiveness and flexibility of technique stands unmatched with other conventional methodology due to the fact that the same test up can be utilized to automate the process of testing separately excited dc motor of higher ratings also. Authors have tested dc motor of ratings up to $5 \mathrm{HP}$ using the same platform. This justifies the universal behavior of the novel technique being implemented by the authors in this paper. In light of the successful results obtained in testing and validation process, and looking at the methodology of automation process discussed in the paper, it is envisaged that all other types of dc motors can also be tested in same automated way

\section{References}

[1] Ianxin Tang, "Real-time DC motor control using the MATLAB interfaced TMS320C31 digital signal processing starter kit (DSK)",Vol.1, Proceedings of the IEEE International Conference on Power Electronics and Drive Systems, pp 321-326,1999.

[2] Nagarajan, R. Jabar, W.A., "Computer-aided testing of a DC motor", Computer-Aided Engineering Journal, pp 67 71 ,June, 1990 .

[3] Meenakshi, M., "Microprocessor Based Digital PID Controller for Speed Control of D.C. Motor", First International Conference on Emerging Trends in Engineering and Technology,pp 960-965, July, 2008.

[4] B.S.Guru, H.R.Hiziroglu, "Electric Machinery and Transformers", A Text Book, 3r d Edition, Oxford, 2001.

[5] Theodore Wildi, "Electrical Machines, Drives, and Power Systems", A Text Book, Sixth Edition, Pearson, 2008.

[6] Edward Hughes, "Electrical and Electronics Technology",10th Edition, Prentice Hill,2008.

[7] John Bird, "Electrical and Electronics Principles and Technology",4th Edition, Elsevier Ltd,2010.

[8] AT Mega32 datasheet

[9] Puneet Kaur, S.Chatterji, Vinod K Sharma, "Design and Development of a Multi-Utility Device for data acquisition, monitoring and Control", National Journal of Engineering \& Technology Education (NJETE), Vol.4, No.1, pp. 31-37, Jun 2010.

[10]Puneet Kaur, S.Chatterji, "Development of Scalable Hardware Abstraction Framework for DC Motor Control Applications", International Journal of Electrical And Electronics Engineering research and Development (IJEEERD), Vol.1, No.1, pp. 18-32, Jun 2011. 


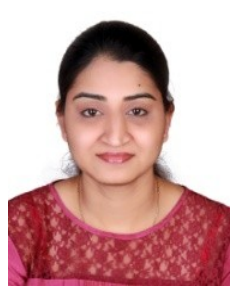

Puneet Kaur received her Degree of Bachelor of Electrical Engineering from Punjab Technical University (India) and Degree of Masters in Power Systems from Panjab University (India) in 2001 and 2004 respectively. She is also pursuing $\mathrm{PhD}$ and presently working as Assistant Professor in department of Electrical and Electronics Engineering of Panjab University (India). She has nine years of experience in the field of teaching. Her research interests cover the field of Power Electronics and Embedded Systems.

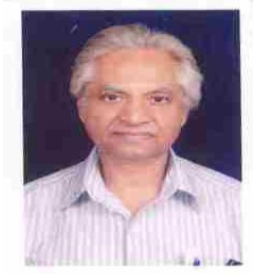

S. Chatterji is presently working as a Professor and Head, Electrical Engineering Department, NITTTR Chandigarh (India). He has 371/2 years of experience out of which $35 \frac{1}{2}$ years are of teaching and 2 years are of Industrial. Dr.S.Chatterji earned his Bachelor of Electrical Engineering from Bhopal University (India), Master of Electrical Engineering from Allahabad University and $\mathrm{PhD}$ from Panjab University, Chandigarh(India). Up till now he has guided more than 100 students for Masters Degree and 10 students for Ph.D. He has more than 150 Research Articles to his credit. He has also authored 3 books in the field of Electronics, $4 \mathrm{Lab}$ Manuals in Electrical and has produced a series of 21 Video films in Power Electronics. His areas of specialization are Power Electronics, Digital Electronics, Electrical Power, ANN, Fuzzy logic applications, Soft Computing Techniques etc. Dr.S.Chatterji is a Fellow member of Institution of Engineers (India), Member of IEEE (USA) and Life member of ISTE. He is also a adjunct professor of Instrumentation and Control, Manipal University. He is also a member of BOS for large number of Universities. 